\title{
Pesticide residues in crops from the south-eastern region of Poland (2012)
}

\author{
Pozostałości środków ochrony roślin w płodach rolnych \\ z terenu południowo-wschodniej Polski (rok 2012)
}

\author{
Ewa Szpyrka, Anna Kurdziel, Aneta Matyaszek, Magdalena Podbielska, \\ Julian Rupar, Magdalena Stowik-Borowiec
}

\section{Summary}

In 2012, a total of 236 crop samples collected from the south-eastern part of Poland were analysed. Pesticide residues were detected in 29 (12\%) analysed samples. No exceeding of Maximum Residue Limits was stated. Among the fungicide residues mostly detected were dithiocarbamates ( $3 \%$ samples) and azoxystrobin ( $2 \%$ ). The insecticide residues detected were mostly related to chlorpyrifos (3\%). The residues of herbicides were found in one sample (flurochloridone in parsley root). In 2012, 7 reports within the Rapid Alert System for Food and Feed were issued and they were concerned with the application of the substances not recommended for a given crop.

Key words: fruit, vegetable, pesticide residue, south-eastern Poland, monitoring

\section{Streszczenie}

W 2012 roku kontroli poddano 236 próbek z terenu południowo-wschodniej Polski. Pozostałości środków ochrony roślin stwierdzono w 29 próbkach (12\%), przy czym w żadnej próbce nie przekroczyły one najwyższych dopuszczalnych poziomów pozostałości (NDP). Najczęściej wykrywanymi fungicydami były: ditiokarbaminiany (3\% analizowanych próbek) i azoksystrobina (2\%). Spośród insektycydów najczęściej stwierdzano pozostałości chloropiryfosu (3\%). Pozostałości herbicydów wykryto tylko w jednej próbce (fluorochloridon w pietruszce). W 2012 roku wystawiono 7 powiadomień w ramach Systemu Wczesnego Ostrzegania o Niebezpiecznej Żywności i Paszach (Rapid Alert System for Food and Feed - RASFF) dotyczących zastosowania środków ochrony roślin niezalecanych do ochrony danej uprawy.

Słowa kluczowe: owoce, warzywa, pozostałości środków ochrony roślin, południowo-wschodnia Polska, monitoring

\footnotetext{
Instytut Ochrony Roślin - Państwowy Instytut Badawczy

Terenowa Stacja Doświadczalna

Langiewicza 28, 35-101 Rzeszów

e.szpyrka@iorpib.poznan.pl
} 


\section{Wstęp / Introduction}

Zgodnie z art. 68 ustawy o ochronie roślin, można stosować wyłącznie środki ochrony roślin (ś.o.r.) dopuszczone do obrotu oraz zgodnie $\mathrm{z}$ etykietą-instrukcją stosowania, ściśle $\mathrm{z}$ podanymi $\mathrm{w}$ niej zaleceniami oraz $\mathrm{w}$ taki sposób, aby nie dopuścić do zagrożenia zdrowia człowieka, zwierząt lub środowiska (Ustawa 2008).

W przypadku zastosowania ś.o.r. niedopuszczonego do obrotu lub zastosowania środka w sposób stwarzający zagrożenie zdrowia człowieka lub zwierząt stosowana jest procedura powiadamiania zgodnie $\mathrm{z}$ systemem wczesnego ostrzegania o niebezpiecznej żywności i paszach (RASFF - Rapid Alert System for Food and Feed).

Laboratorium Badania Pozostałości Środków Ochrony Roślin (LBPŚOR) Instytutu Ochrony Roślin - Państwowego Instytutu Badawczego (IOR - PIB) w Rzeszowie prowadzi badania pozostałości ś.o.r. w ramach urzędowej kontroli płodów rolnych, której celem jest sprawdzenie prawidłowości stosowania ś.o.r.

\section{Materiały i metody / Materials and methods}

W 2012 roku kontroli poddano 236 próbek roślinnych należących do 36 upraw. Próbki do badań zostały pobrane przez inspektorów Państwowej Inspekcji Ochrony Roślin i Nasiennictwa z terenu południowo-wschodniej Polski.

Program kontroli obejmował oznaczenie 166 substancji czynnych ś.o.r. wraz z metabolitami (tab. 1). Pozostałości fungicydów benzimidazolowych (karbendazym) oznaczano metoda bioautografii (Murawska 1980). Do analizy pozostałych substancji czynnych wymienionych w tabeli 1 . stosowano akredytowane, według PN-EN ISO/IEC 17025 (2005), metody badawcze: spektrofotometrii (ditiokarbaminiany) (Chmiel 1979) oraz chromatografii gazowej połączonej z dualnym systemem detekcji (wychwytu elektronów i azotowo-fosforowym) (Grzegorzak i wsp. 2012).

Uzyskane wyniki porównywano z normami określającymi najwyższe dopuszczalne poziomy pozostałości (NDP) (Rozporządzenie 2005).

Tabela 1. Analizowane substancje czynne oraz granice ich oznaczalności

Table 1. Analysed substances and their limits of determination

\begin{tabular}{|c|c|}
\hline Insektycydy & 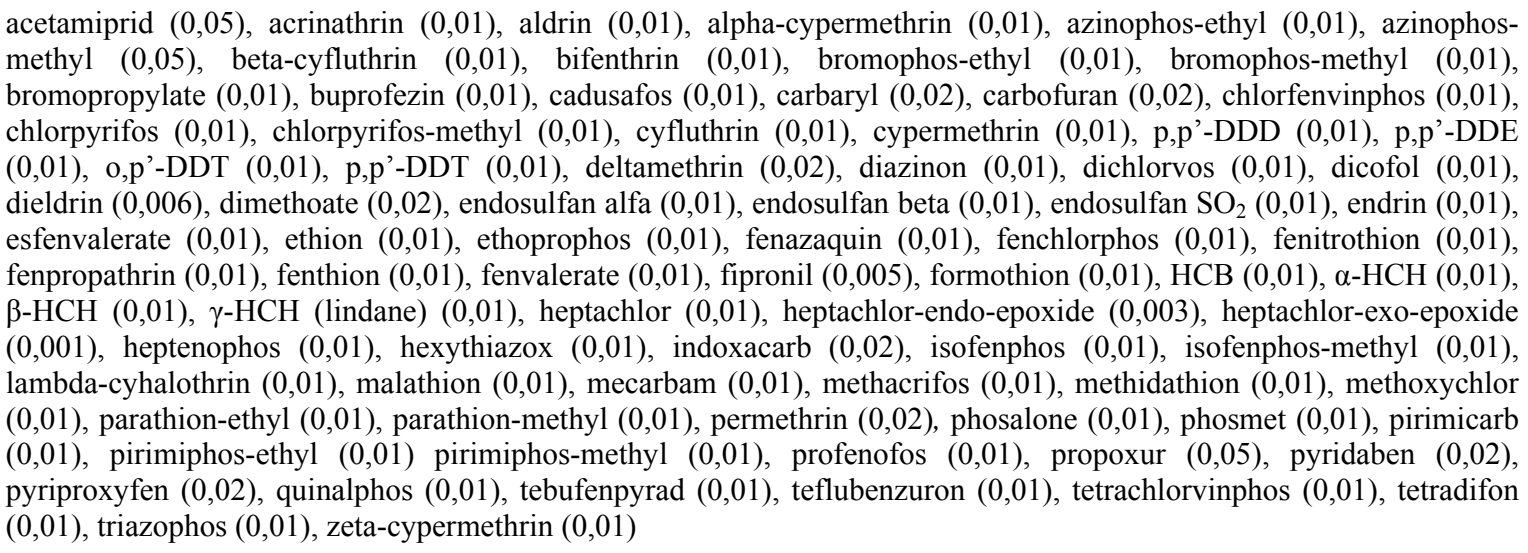 \\
\hline Fungicides & $\begin{array}{l}\text { azaconazole }(0,01) \text {, azoxystrobin }(0,01) \text {, benalaxyl }(0,05) \text {, bitertanol }(0,05) \text {, boscalid }(0,01) \text {, bromuconazole }(0,01) \text {, } \\
\text { bupirimate }(0,01) \text {, captan }(0,02) \text {, carbendazim }(0.05) \text {, chlorothalonil }(0,01) \text {, cyproconazole }(0,01) \text {, cyprodinil }(0,02) \text {, } \\
\text { dichlofluanid }(0,01) \text {, dicloran }(0,01) \text {, difenoconazole }(0,01) \text {, dimethomorph }(0,01) \text {, dimoxystrobin }(0,01) \text {, diniconazole } \\
(0,01) \text {, diphenylamine }(0,05) \text {, dithiocarbamates (mancozeb, maneb, metiram, propineb, thiram, zineb, ziram) }(0,05) \text {, } \\
\text { epoxiconazole }(0,01) \text {, fenarimol }(0,01) \text {, fenbuconazole }(0,02) \text {, fenhexamid }(0,05) \text {, fenpropimorph }(0,02) \text {, fludioxonil } \\
(0,01) \text {, fluquinconazole }(0,01) \text {, flusilazole }(0,01) \text {, flutriafol }(0,02) \text {, folpet }(0,01) \text {, hexaconazole }(0,01) \text {, imazalil }(0,02) \text {, } \\
\text { imibenconazole }(0,01) \text {, iprodione }(0,02) \text {, krezoxim-methyl }(0,01) \text {, mepanipyrim }(0,01) \text {, metalaxyl }(0,01) \text {, metconazole } \\
(0,02) \text {, myclobutanil }(0,01) \text {, oxadixyl }(0,01) \text {, penconazole }(0,01) \text {, pencycuron }(0,05) \text {, picoxystrobin }(0,01) \text {, prochloraz } \\
(0,01) \text {, procymidone }(0,01) \text {, propiconazole }(0,01) \text {, pyrazophos }(0,01) \text {, pyrimethanil }(0,01) \text {, quinoxyfen }(0,01) \text {, } \\
\text { quintozene }(0,01) \text {, tebuconazole }(0,02) \text {, tecnazene }(0,01) \text {, tetraconazole }(0,01) \text {, tolclofos-methyl }(0,01) \text {, tolylfluanid } \\
(0,01) \text {, triadimefon }(0,01) \text {, triadimenol }(0,01) \text {, trifloxystrobin }(0,01) \text {, vinclozolin }(0,01) \text {, zoxamide }(0,01)\end{array}$ \\
\hline Herbicydy & $\begin{array}{l}\text { acetochlor }(0,01) \text {, atrazine }(0,01) \text {, bromacil }(0,01) \text {, chlorpropham }(0,01) \text {, cyanazine }(0,01) \text {, cyprazine }(0,01) \text {, diflufenican } \\
(0,01) \text {, flurochloridone }(0,01) \text {, lenacil }(0,05) \text {, linuron }(0,05) \text {, metribuzin }(0,01) \text {, metazachlor }(0,01) \text {, napropamide }(0,05) \text {, } \\
\text { nitrofen }(0,01) \text {, oxyfluorfen }(0,01) \text {, pendimethalin }(0,02) \text {, prometryn }(0,01) \text {, propachlor }(0,01) \text {, propaquizafop }(0,05) \text {, } \\
\text { propazine }(0,01) \text {, propham }(0,02) \text {, propyzamide }(0,01) \text {, simazine }(0,01) \text {, trifluralin }(0,01)\end{array}$ \\
\hline $\begin{array}{l}\text { Regulatory } \\
\text { wzrostu } \\
\text { Growth } \\
\text { regulators }\end{array}$ & paclobutrazol $(0,01)$ \\
\hline
\end{tabular}

W nawiasach podano granice oznaczalności w $\mathrm{mg} / \mathrm{kg}$ - The limits of determination were given in brackets in $\mathrm{mg} / \mathrm{kg}$ 
W 2012 roku LBPŚOR uczestniczyło w międzynarodowych badaniach biegłości organizowanych przez Unię Europejska, których program obejmował oznaczanie pozostałości ś.o.r. zarówno w owocach, warzywach, jak i zbożach. Podobnie, jak w latach ubiegłych, także i w tym roku laboratorium uzyskało poprawne wyniki, co dowodzi, iż system kontroli poziomu pozostałości jest prawidłowy i zapewnia uzyskiwanie poprawnych wyników.

\section{Wyniki i dyskusja / Results and discussion}

Wykonano analizy 236 próbek pochodzenia roślinnego, z których $22 \%$ stanowiły owoce, $48 \%$ warzywa, a 30\% zboża. Pozostałości ś.o.r. stwierdzono w 29 próbkach (12\%), przy czym w żadnej próbce nie przekroczyły one poziomu NDP. Podobnie, jak w przypadku monitoringu prowadzonego na terenie całej Polski oraz krajów Unii

Tabela 2. Pozostałości ś.o.r. w płodach rolnych (2012)

Table 2. Pesticide residues detected in crops (2012)

\begin{tabular}{|c|c|c|c|c|c|c|}
\hline \multirow{2}{*}{$\begin{array}{l}\text { Uprawa } \\
\text { Crop }\end{array}$} & \multirow{2}{*}{$\begin{array}{c}\text { Liczba } \\
\text { badanych próbek } \\
\text { Number } \\
\text { of analysed samples }\end{array}$} & \multirow{2}{*}{$\begin{array}{l}\text { Substancja czynna } \\
\text { Active substance }\end{array}$} & \multirow{2}{*}{$\begin{array}{l}\text { Liczba próbek } \\
\text { z pozostałościami } \\
\text { No. of samples } \\
\text { with residues }\end{array}$} & \multicolumn{2}{|c|}{$\begin{array}{c}\text { Zakres wykrywanych } \\
\text { pozostałości } \\
\text { Range of found residues }\end{array}$} & \multirow{2}{*}{$\begin{array}{c}\text { NDP } \\
\text { MRL } \\
{[\mathrm{mg} / \mathrm{kg}]}\end{array}$} \\
\hline & & & & $\begin{array}{c}\min \\
{[\mathrm{mg} / \mathrm{kg}]}\end{array}$ & $\begin{array}{c}\max \\
{[\mathrm{mg} / \mathrm{kg}]}\end{array}$ & \\
\hline $\begin{array}{l}\text { Gruszka } \\
\text { Pear }\end{array}$ & 8 & $\begin{array}{c}\text { dithiocarbamates } \\
\text { captan } \\
\text { pyrimethanil }\end{array}$ & $\begin{array}{l}3 \\
3 \\
1 \\
\end{array}$ & $\begin{array}{l}0,05 \\
0,07 \\
0,18 \\
\end{array}$ & $\begin{array}{c}0,58 \\
0,16 \\
-\end{array}$ & $\begin{array}{l}5 \\
3 \\
5 \\
\end{array}$ \\
\hline $\begin{array}{l}\text { Kapusta pekińska } \\
\text { Chinese cabbage }\end{array}$ & 9 & chlorpyrifos & 2 & 0,02 & 0,03 & 0,5 \\
\hline $\begin{array}{l}\text { Malina } \\
\text { Raspberry }\end{array}$ & 10 & iprodione & 1 & 0,16 & - & 10 \\
\hline $\begin{array}{l}\text { Ogórek spod osłon } \\
\text { Greenhouse } \\
\text { cucumber }\end{array}$ & 5 & azoxystrobin $^{1}$ & 1 & 0,02 & - & 1 \\
\hline $\begin{array}{l}\text { Ogórek gruntowy } \\
\text { Field cucumber }\end{array}$ & 10 & $\begin{array}{l}\text { chlorpyrifos }{ }^{1} \\
\text { chlorothalonil }\end{array}$ & $\begin{array}{l}1 \\
1 \\
\end{array}$ & $\begin{array}{l}0,03 \\
0,01 \\
\end{array}$ & $\begin{array}{l}- \\
- \\
\end{array}$ & $\begin{array}{c}0,05 \\
1 \\
\end{array}$ \\
\hline $\begin{array}{l}\text { Papryka spod osłon } \\
\text { Greenhouse sweet } \\
\text { pepper }\end{array}$ & 5 & $\begin{array}{l}\text { azoxystrobin } \\
\text { iprodione }^{1}\end{array}$ & $\begin{array}{l}1 \\
1\end{array}$ & $\begin{array}{l}0,02 \\
0,13\end{array}$ & $\begin{array}{l}- \\
-\end{array}$ & $\begin{array}{l}3 \\
5\end{array}$ \\
\hline $\begin{array}{l}\text { Pieczarka } \\
\text { Mushroom }\end{array}$ & 3 & prochloraz & 1 & 0,86 & - & 3 \\
\hline $\begin{array}{l}\text { Pietruszka korzeń } \\
\text { Parsley root }\end{array}$ & 3 & flurochloridone & 1 & 0,03 & - & 0,1 \\
\hline $\begin{array}{l}\text { Pomidor spod osłon } \\
\text { Greenhouse tomato }\end{array}$ & 8 & $\begin{array}{l}\text { azoxystrobin } \\
\text { bupirymate } \\
\text { chlorothalonil } \\
\text { cyprodinil } \\
\text { fludioxonil } \\
\end{array}$ & $\begin{array}{l}2 \\
1 \\
2 \\
1 \\
1 \\
\end{array}$ & $\begin{array}{l}0,02 \\
0,29 \\
0,05 \\
0,01 \\
0,02 \\
\end{array}$ & $\begin{array}{c}0,14 \\
- \\
0,81 \\
- \\
- \\
\end{array}$ & $\begin{array}{l}3 \\
2 \\
2 \\
1 \\
1 \\
\end{array}$ \\
\hline $\begin{array}{l}\text { Porzeczka czarna } \\
\text { Black currant }\end{array}$ & 8 & $\begin{array}{l}\text { lambda-cyhalothrin } \\
\text { dithiocarbamates } \\
\text { fenazaquin }^{1} \\
\end{array}$ & $\begin{array}{l}2 \\
1 \\
1 \\
\end{array}$ & $\begin{array}{l}0,02 \\
0,62 \\
0,02 \\
\end{array}$ & $\begin{array}{l}- \\
- \\
- \\
\end{array}$ & $\begin{array}{c}0,2 \\
5 \\
0,01 \\
\end{array}$ \\
\hline $\begin{array}{l}\text { Pszenica } \\
\text { Wheat }\end{array}$ & 46 & pirimiphos-methyl & 2 & 0,05 & 1,36 & 5 \\
\hline $\begin{array}{l}\text { Sałata gruntowa } \\
\text { Field salad }\end{array}$ & 2 & azoxystrobin & 1 & 0,07 & - & 3 \\
\hline $\begin{array}{l}\text { Seler korzeniowy } \\
\text { Celery root }\end{array}$ & 3 & chlorpyrifos $^{1}$ & 2 & 0,02 & 0,08 & 0,05 \\
\hline $\begin{array}{l}\text { Truskawka } \\
\text { Strawberry }\end{array}$ & 13 & $\begin{array}{l}\text { alpha-cypermethrin } \\
\text { dithiocarbamates } \\
\text { fenazaquin } \\
\text { folpet } \\
\text { pyrimethanil } \\
\text { tetraconazole } \\
\text { trifloxystrobin } \\
\end{array}$ & $\begin{array}{l}1 \\
2 \\
1 \\
1 \\
2 \\
2 \\
1\end{array}$ & $\begin{array}{l}0,02 \\
0,33 \\
0,02 \\
0,03 \\
0,02 \\
0,01 \\
0,01 \\
\end{array}$ & $\begin{array}{c}- \\
2,9 \\
- \\
- \\
- \\
0,04 \\
- \\
\end{array}$ & $\begin{array}{c}0,07 \\
10 \\
1 \\
3 \\
5 \\
0,2 \\
0,5 \\
\end{array}$ \\
\hline $\begin{array}{l}\text { Ziemniak } \\
\text { Potatoes }\end{array}$ & 17 & chlorpyrifos $^{1}$ & 1 & 0,01 & - & 0,05 \\
\hline
\end{tabular}

NDP - najwyższe dopuszczalne poziomy pozostałości - MRL - maximum residue limits

${ }^{1}$ substancja, której stosowanie nie jest zalecane w danej uprawie - application of the substance not recommended for a given crop 
Europejskiej, również w południowo-wschodniej Polsce najwięcej pozostałości ś.o.r. występowało w owocach (22\% wszystkich próbek owoców), warzywach (15\%), natomiast najmniej w zbożach (3\%) (Nowacka i wsp. 2011, 2012; Scientific Report of EFSA 2013). W porównaniu do lat ubiegłych pozostałości stwierdzano znacznie rzadziej (Słowik-Borowiec i wsp. 2011; Szpyrka i wsp. 2012). Mogło to być spowodowane dużym udziałem roślin rolniczych w asortymencie badanych próbek (30\% zbóż i $12 \%$ ziemniaków), w których pozostałości ś.o.r. stwierdza się znacznie rzadziej niż w owocach i warzywach (Nowacka i wsp. 2011, 2012; Rupar i wsp. 2011; Scientific Report of EFSA 2013).

W jednej próbce selera stwierdzono pozostałość chloropiryfosu na poziomie $0,08 \mathrm{mg} / \mathrm{kg}$ (NDP wynosi $0,05 \mathrm{mg} / \mathrm{kg}$ ), a w próbce porzeczki czarnej wykryto pozostałość fenazachiny równą $0,02 \mathrm{mg} / \mathrm{kg}$ (NDP wynosi $0,01 \mathrm{mg} / \mathrm{kg}$ ). Wyniki te po uwzględnieniu niepewności metody nie przekroczyły NDP (SANCO 2011).

Podobnie, jak w latach ubiegłych najczęściej stwierdzano pozostałości fungicydów (Słowik-Borowiec i wsp. 2011; Szpyrka i wsp. 2012). Najczęściej wykrywanymi związkami należącymi do tej grupy były ditiokarbaminiany (3\% analizowanych próbek) i azoksystrobina (2\%). Spośród insektycydów najczęściej stwierdzano pozostałości chloropiryfosu (3\%). Pozostałości herbicydów wykryto tylko w jednej próbce (fluorohloridon w pietruszce).

W badanych próbkach stwierdzono obecność pozostałości wielokrotnych. W 1 próbce truskawki wykryto obecność 4 związków, w 1 próbce gruszki i 1 próbce pomidora spod osłon - 3 substancje, w 8 próbkach (2 próbki gruszek, 2 próbki pomidora spod osłon, 2 próbki porzeczki czarnej, 2 próbki truskawki) - 2 substancje, a w pozostałych 18 1 substancję. Szczegółowe dane o poziomach pozostałości ś.o.r. zamieszczone zostały w tabeli 2 .

W 2012 roku wystawiono 7 powiadomień w ramach systemu RASFF dotyczących zastosowania ś.o.r. niezalecanych do ochrony danej uprawy. 4 powiadomienia doty- czyły zastosowania ś.o.r. zawierającego chloropiryfos w uprawie: ogórka gruntowego, selera (2 próbki) i ziemniaka. Kolejne 3 powiadomienia dotyczyły występowania pozostałości azoksystrobiny w uprawie ogórka spod osłon, iprodionu w papryce spod osłon oraz fenazachiny w porzeczce czarnej. Sięganie przez producentów po środki niezalecane jest związane głównie $\mathrm{z}$ brakiem odpowiednich preparatów zarejestrowanych do ochrony danej uprawy (Nowacka i wsp. 2011, 2012; Szpyrka i wsp. 2012).

Większość, tj. 88\% próbek materiału roślinnego nie zawierało wykrywalnych pozostałości (powyżej granic oznaczalności stosowanych metod analitycznych). Do próbek tych należały: agrest (1 - liczba badanych próbek), bobik (2), borówka amerykańska (1), bób (1), brokuł (3), burak ćwikłowy (4), cebula (6), fasola szparagowa (9), groch (3), jabłko (3), jęczmień (16), kalafior (4), kapusta (12), marchew (2), mieszanka zbóż (3), por (2), porzeczka czerwona (1), pszenżyto (4), sałata spod osłon (1), wiśnia (6) oraz żyto (2).

\section{Wnioski / Conclusions}

1. W roku 2012 wykonano analizy 236 próbek materiału roślinnego. Pozostałości ś.o.r. stwierdzono w 29 próbkach $(12 \%)$, przy czym w żadnej próbce nie przekroczyły one poziomu NDP.

2. Najczęściej wykrywanymi fungicydami były ditiokarbaminiany (3\% analizowanych próbek) i azoksystrobina $(2 \%)$. Spośród insektycydów najczęściej stwierdzano pozostałości chloropiryfosu (3\%). Pozostałości herbicydów stwierdzono tylko w jednej próbce (fluorochloridon w pietruszce).

3. Nieprawidłowości związane ze stosowaniem ś.o.r. dotyczyły wyłącznie zastosowania ś.o.r. niezalecanych do ochrony danej uprawy.

\section{Literatura / References}

Chmiel Z. 1979. Spektrofotometryczne oznaczanie śladowych pozostałości dwutiokarbaminianów w materiale roślinnym. Chemia Anal. 24: $505-511$.

Grzegorzak M., Szpyrka E., Słowik-Borowiec M., Kurdziel A., Matyaszek A., Rupar J. 2012. Potential risk to consumer related with occurrence of pesticide residues in early vegetables. Ecol. Chem. Eng. A, 19 (3): 239-248. DOI: 10.2428/ecea.2012.19(03)025.

Murawska M. 1980. Metoda bioautografii w zastosowaniu do oznaczania śladowych ilości fungicydów benzimidazolowych. Prace Nauk. Inst. Ochr. Roślin 22 (1): 139-149.

Nowacka A., Gnusowski B., Walorczyk S., Drożdżyński D., Raczkowski M., Hołodyńska A., Frąckowiak D., Wójcik A., Ziółkowski A., Rzeszutko U., Domańska I., Jurys J., Łozowicka B., Kaczyński P., Rutkowska E., Jankowska M., Hrynko I., Szpyrka E., Rupar J., Rogozińska K., Kurdziel A., Słowik-Borowiec M., Michel M., Kuźmenko A., Szala J. 2011. Pozostałości środków ochrony roślin w płodach rolnych (rok 2010). [Pesticide residues in polish crops (2010)]. Prog. Plant Prot./Post. Ochr. Roślin 51 (4): $1723-1738$.

Nowacka A., Gnusowski B., Walorczyk S., Drożdżyński D., Raczkowski M., Hołodyńska A., Frąckowiak D., Wójcik A., Ziółkowski A., Przewoźniak M., Swoboda W., Rzeszutko U., Domańska I., Jurys J., Łozowicka B., Kaczyński P., Rutkowska E., Jankowska M., Hrynko I., Szpyrka E., Rupar J., Rogozińska K., Kurdziel A., Słowik-Borowiec M., Szala J., Szponik M., Michel M. 2012. Pozostałości środków ochrony roślin w płodach rolnych (rok 2011). [Pesticide residues in Polish crops (2011)]. Prog. Plant Prot./Post. Ochr. Roślin 52 (4): 1106-1116.

PN-EN ISO/IEC 17025. 2005. Ogólne wymagania dotyczące kompetencji laboratoriów badawczych i wzorcujących. Polski Komitet Normalizacyjny, Warszawa, 42 ss.

Rozporządzenie (WE) nr 396/2005 Parlamentu Europejskiego i Rady z dnia 23 lutego 2005 r. zmieniające dyrektywę Rady 91/414/EWG w sprawie najwyższych dopuszczalnych poziomów pozostałości pestycydów w żywności i paszy pochodzenia roślinnego i zwierzęcego oraz na ich powierzchni (Dz. Urz. UE, L 70, z dnia 16.03.2005 r., z późn. zm.), 16 ss. 
Rupar J., Rogozińska K., Szpyrka E., Słowik-Borowiec M., Kurdziel A. 2011. Kontrolne badania pozostałości środków ochrony roślin w paszach pochodzenia roślinnego wykonane przez laboratorium Terenowej Stacji Doświadczalnej Instytutu Ochrony Roślin Państwowego Instytutu Badawczego w Rzeszowie w latach 2006-2010. [Monitoring of pesticide residues in feed of plant origin carried out in laboratory of Experimental Station of the Institute of Plant Protection - National Research Institute in Rzeszów in 2006-2010]. Prog. Plant Prot./Post. Ochr. Roślin 51 (1): 383-386.

SANCO/12495/2011. 2011. Method Validation and Quality Control Procedures for Pesticide Residues Analysis in Food and Feed, 40 pp.

Scientific Report of EFSA 2013. The 2010 European Union Report on Pesticide Residues in Food. EFSA J. 11 (3): 3130,209 pp. DOI: 10.2903/j.efsa.2013.3130.

Słowik-Borowiec M., Szpyrka E., Kurdziel A., Grzegorzak M., Rupar J., Rogozińska K. 2011. Kontrola poziomów pozostałości środków ochrony roślin w owocach i warzywach z terenu południowo-wschodniej Polski. [Pesticide residues in fruit and vegetables from south-eastern Poland]. Prog. Plant Prot./Post. Ochr. Roślin 51 (2): 740-746.

Szpyrka E., Kurdziel A., Grzegorzak M., Rupar J., Słowik-Borowiec M., Matyaszek A. 2012. Pozostałości środków ochrony roślin w płodach rolnych z terenu południowo-wschodniej Polski. [Pesticide residues in crops from the south-eastern region of Poland]. Prog. Plant Prot./Post. Ochr. Roślin 52 (1): 149-152.

Ustawa z dnia 18 grudnia 2003 r. o ochronie roślin (Dz. U. 2008, Nr 133, poz. 849, tekst jednolity), 85 ss. 